lofibrosis are some of the other abnormalities described in association with tuberculosis. Such manifestations often confuse the clinical picture. Awareness and prompt recognition would help in adopting appropriate therapeutic measures early.

\section{References}

1. Fountain JR. Blood changes associated with disseminated tuberculosis. Br Med J 1954; 2 : 76-81

2. Twomey JJ, Leavell BS. Leukemoid reaction to tuberculosis. Arch Int Med 1965; 116 : 21-28

3. Classer RM, Welker RI, Herion JC. The significance of hematologic abnormalities in patients with tuberculosis. Arch Int Med 1970; $125: 691-694$

4. Corr WP, Kyle RA. Bowie EJW. Hematologic changes in tuberculosis. Am J Med Sci 1964; 248, 2 : 709-714

5. Ball K, Joules H, Pagel W. Acute tuberculous septicemia with leucopenia. Br Med J 1951; $2: 869-871$
6. Oswald NC. Acute tuberculosis and granulocytic disorders. Br Med J 1963; 2 : 1489-1492

7. Mills E, Townsend S. Leukemoid blood pictures in tuberculosis. Can Med Assoc $\mathbf{J}$ $1937 ; 37: 56-59$

8. Garener EH, Mettier R. Lympholeukemoid reaction of blood associated with miliary tuberculosis. Blood 1949; 4 : 764-769

9. Wiseman BK, Dean CA. The lymphatic reaction in tuberculosis. Am Rev Tub 1934; 30: 33-37

10. Feldman WH, Stasney J. Leukemoid response of tuberculous rabbits to administration of tuberculoprotein. Am J Med Sci 1937; 30 : 33-37

11. Plarmain G, Lycette RR, Ritzerald PB. Tuberculin induced mitosis in peripheral blood leucocytes. Lancet $1963 ;$ i : 637-638

12. Mavlight GM, Binder RA, Crosky WH. Disseminated intravascular coagulation in miliary tuberculosis. Arch Int Med 1972; 130 : 388-390

13. Hurby $\mathrm{JH}_{\mathrm{H}}$, Hudson LD. Miliary tuberculosis and adult respiratory distress syndrome. Ann Int Med 1976; $85: 609-611$

14. Goburn RJ, England JM, Samson DM et al. Tuberculosis and blood disorders. Br J Hematol $1973 ; 25: 793-799$

\title{
RELATION OF INFANT HEART TO STERNUM: ITS SIGNIFICANCE IN CARDIOPULMONARY RESUSCITATION
}

Present guidelines for infant resuscitation suggest that external cardiac conpression should be applied over the middle third of the sternum. This recommendation is based on a study of 20 infant cadavers. However, a more recent report showed that external cardiac massage was more effective when applied over the lower third of the sternum: this same report also stated that the heart is situated under the lower third of the sternum, although detailed evidence was not provided. We have now attempted to establish the true position of the heart in the infant chest.

In a radiographic study of 55 infants with an age-range of 27 weeks' gestation to 13 months post-term, the centre of the heart was positioned under the lower third of the sternum in 48 cases. In 4 infants the position was slightly more cephalad, but still below the lower half of the sternum. In 3 infants, the position was below the xiphisternal junction. We therefore believe the present guidelines for infant resuscitation should be revised, and that external cardiac compression should be applied over the lower rather than the middle third of the sternum. 